\title{
A new family of ceraphronoid wasps from Early Cretaceous Álava Amber, Spain
}

Jaime Ortega-Blanco, Alexander P. Rasnitsyn, and Xavier Delclòs

Acta Palaeontologica Polonica 55 (2), 2010: 265-276 doi: http://dx.doi.org/10.4202/app.2009.0014

Radiophronidae, a new ceraphronoid fossil family including two new genera and species, is described here from the Early Cretaceous (Albian) amber from the Basque Cantabrian Basin (Spain). Radiophron ibericus gen. et sp. nov. and Microcostaphron parvus gen. et sp. nov. are described from eight and one specimens respectively. The new fossils show some similarities with the extinct family Stigmaphronidae but are distinguished from it and the extant ceraphronoids mainly by the presence of not fused radial and costal veins, among other characteristics. A first cladistic analysis retrieves Radiophronidae as the basal sister-group to all other ceraphronoids (Ceraphronidae, Megaspilidae, and Stigmaphronidae).

Key words: Hymenoptera, Radiophronidae, Ceraphronoidea, amber, Albian, Basque Country, Spain.

Jaime Ortega-Blanco [j.ortega.blanco@ub.edu] and Xavier Delclòs [xdelclos@ub.edu ], Dep. d'Estratigrafia, Paleontologia i Geociències Marines, Facultat de Geologia, Universitat de Barcelona, 08071 Barcelona, Spain; Alexander P. Rasnitsyn [rasna36@yahoo.com], Paleontological Institute, Russian Academy of Sciences, Profsoyuznaya Str. 123, 117997, Moscow, Russia, and Natural History Museum, Cromwell Road SW7 5BD, London, England.

This is an open-access article distributed under the terms of the Creative Commons Attribution License (for details please see creativecommons.org), which permits unrestricted use, distribution, and reproduction in any medium, provided the original author and source are credited. 
